\title{
The Application of Traditional Chinese Wash Painting in the Modern Fashion Clothing Design
}

\author{
Zhuanye Zhao ${ }^{1} \&$ Cheng $\mathrm{Lu}^{2}$ \\ ${ }^{1}$ Fashion Design and Engineering, Shanghai University of Engineering Science, shanghai, China \\ Correspondence: Cheng Lu, Associate Professor, College of fashion, Shanghai University of Engineering Science, \\ China.E-mail:jilabo@126.com
}

Received: April 17, 2015

Accepted: April 24, 2015

Online Published: April 27, 2015

doi:10.5430/jbar.v4n1p49

URL: http://dx.doi.org/10.5430/jbar.v4n1p49

\begin{abstract}
With the development of times, great changes have taken place on people's appreciation of the beauty and demand about garment. The decoration of garment as well as individual character become the trend of times gradually. Chinese traditional wash painting is an important part of Chinese culture, in design of clothing, its special expressive force is a good choice for designer expressing themselves. Therefore, this element is popular among every fashion shows. Because of financial crisis, the road of Chinese export trade is becoming more and more severe, it's urgent for China to create a road which is full of Chinese culture, the Chinese traditional wash painting is a inspiration origin for native designer. On the base of achievement which is discussed in the past, this paper will pay attention to the similarity between wash painting and garment design as well as the element apply to garment.
\end{abstract}

Keywords: Garment design, Traditional Chinese wash painting, Innovative use, Modern fashion clothing

\section{Introduction}

With the development of economy and the improvement of people's material and spiritual living conditions, people are no longer just the pursuit of clothing for staying warm in it, modesty and other basic functions , the decorative of the clothing and personality expression become a critical factor when people choose clothing. Chinese traditional wash painting, as one of the important part of Chinese culture, widely welcomed by the designers because of its unique form of expression and artistic beauty. The modern fashion clothing combining the Chinese traditional wash painting elements also sought after by many consumers.

The deepening of globalization and the foreign culture, on the one hand, promotes a better understanding of our world, but it also forms a certain impact on our Chinese traditional culture on the other hand, lots of Chinese culture is slowly disappearing in the modernization process. (Xue Shuqin, 2006) For better promotion to Chinese traditional culture and successful transformation of the clothing industry in China, the combination of Chinese traditional culture and clothing design is a growing trend, is the only path to go with Chinese characteristics apparel development. Therefore, the study of use of traditional Chinese wash painting on the modern fashion design to promote Chinese traditional culture and adapt to the development of modern clothing is valuable.

Chinese traditional wash painting is the treasure of Chinese nation culture, but also an indispensable chapter in the history of world art of painting, thus through the ages, researches with regard to it never stopped, but the study about the application of it in clothing design is not much more special, foreign scholars on such research is less. And because of the impact of the global financial crisis and the rising cost of raw materials and labor, the development of domestic apparel industry to go a single way of OEM is increasingly difficult, it is urgently needed to develop a innovation development way with Chinese characteristics for them. So the Chinese traditional culture elements, such as traditional Chinese wash painting, will undoubtedly become a great source of inspiration for the local garment designers, research on its use in the clothing is necessary obviously.

According to lots of previous research related to the use of Chinese wash painting on the garment design and relevant books such as wash painting, clothing structure design, it is found that related research is not particularly in-depth, many of which are inductive summary, only staying the state that list presentation about the use of wash painting elements or simple similarity analysis on wash painting and clothing. The research based on the combination of wash painting elements and modern garment is minimal, most of which focus on haute couture clothing in particular and there is no extensive practical value. 
This paper will make summary to some degree and explore the underlying value, the local brands "South commoner" to be analyzed for an example, focuses on how Chinese traditional wash painting specifically applied to modern public garment, in which way there is a balance between aesthetics and practicality, and the significance of it.

\section{Chinese traditional wash painting}

While Western painting is a kind of art that strikes people through the form, Chinese traditional wash painting which put its emphasis on depicting imagery and conveying romantic charm through imagery is quite different from the Western art. Heinz Paetzold, in his paper "The Origins of Painting: An Intercultural Perspective", deeply analyses the difference between the traditional Chinese wash painting and western landscape painting and the technique of expression separately, the item of the origin of landscape painting also explored. In his statement, Chinese landscape painting has reached the top of the mountain (Heinz Paetzold, 2009). However, because of the existence of cultural differences, understanding of Westerners for Chinese wash painting not particularly deep.

From the perspective of the Chinese scholars, most believe that Chinese traditional wash painting is a kind of having lasting appeal painting, which, using ink as main raw material with different amount of water, forms different sorts of state of the ink and the image of different levels of black, white, gray composed ultimately (Hu Bo, Jia jingsheng, 2010), shown in figure 1, figure 2. It emphasizes the romantic charm, is a high level of mind state. Black and white are the essences of traditional Chinese wash color, which, is generally used to convey the painter's aesthetic ideas and unique sense of beauty (Wu Shanming, 2010). In my sense, white rice paper is the skin of Chinese traditional wash painting, ink is the skeleton, water is blood and ink rhyme is the soul above all. They are inseparable and the perfect combination of all the parts does constitute the amazing ink Art.

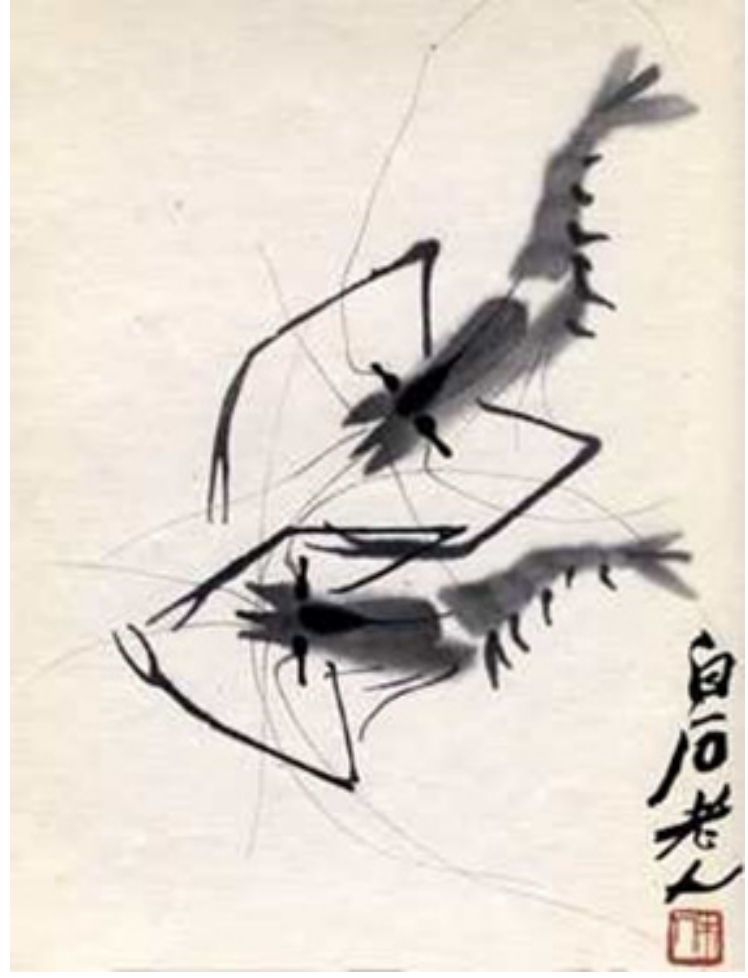

Figure 1. Chinese traditional painting by QiBaishi

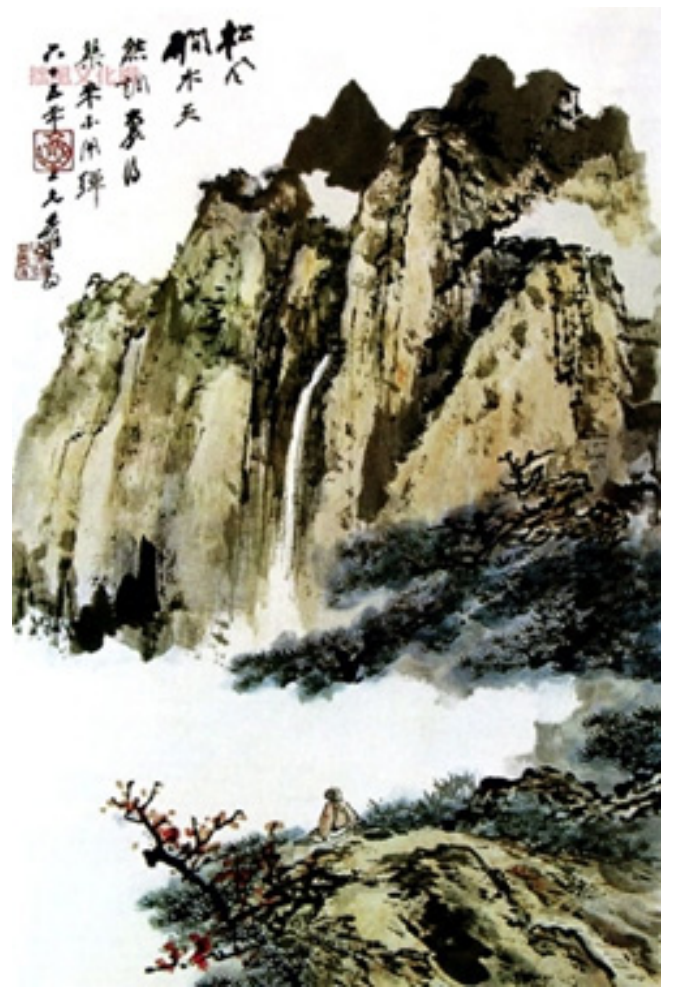

Figure 2. Chinese traditional painting

by Zhang Daqian

\section{The link between Chinese traditional wash painting and garment}

As for the Chinese garment, there are pretty of similarities between the Chinese traditional wash painting and it, better performance of connectivity also be shown, which forms theoretical basis about Chinese traditional wash painting reasonably applied to the garment exactly. XieHe of southern dynasty, in his "The tasting record of ancient paintings", had a very insightful views on Chinese traditional wash painting. He claimed that Chinese traditional 
wash painting pay attention to "Vivid rhythm", "Writing a God-shaped" and "Bone pen". Though the statement is brief, It's the better explanation of the characteristics of Chinese painting art (Gao Yuan, Zhang Yan, 2011).

\section{1 the connectivity on the layering}

Chinese traditional ink painting is a kind of art type full of layering. Either from the layout of the whole pictures or scenery description represented in the painting, the artist is focused on layering of the picture. For instance, the faraway mountains and nearby water, the artist create a feeling of layering according to lighter or heavier ink (Kou Yuanxun, 2006). Similarly, in the field of fashion design, the conception of layering also widely used by designers to express arts aesthetic feeling. Any a piece of clothing accepted or approved by public is layered clothing which have a visual focus and clear theme while some, with no layering, give observer a kind of messy feeling. The wash clothing, designed by Luo Zheng in 2009, with the gradual change of black-and-white and smooth cut, have a clear layering and are full of flavor. Then we will find that they are so similar, is to highlight the theme and which is the joint point for their blend use. Chinese wash painting's composition skills give fashion designer inspiration while the success of China-Chinese style clothing is also a kind of expression and advocation for Chinese traditional art (Zhou Meng, 2009).

\section{2 the connectivity on color}

Chinese traditional wash painting with white at the bottom, through the change of black, white, grey, convey the rhyme of wash painting." Even the most simple black, also can achieve the effect of hearty." (Sun Yanan, Zhang Xing, 2009) This is a scholar Sun Yanan, Zhang Xing description of Chinese wash painting, simple but insightful. It was ink may blend with the different amount of water that formed the gradations of color rich in content, creating a unique style of painting (Wang Feifei, 2002).

"Black and white can be described as the soul of color of ink art, transformation between black and white embodies more ancient Chinese philosophy of dialectical thinking." (Song Ningning, 2013) As such, for the clothing design, black, white, gray is also the classic hue designer loves, is an integral part of the major fashion shows. As shown in figure 3, ink wind dress designed by GuoPei, which make Li Bingbing widely praised by the media on the closing ceremony of Pusan International Film Festival, as well as in figure 4, the Chinese wind dress masterpiece of Lawrence $\mathrm{Xu}$ - Go over the Snow in search of Plums, also let Fan bingbing to shine on the 57th Berlin Film Festival in 2007. Modern fashions can be designed as ink painting in black, white, gray, looking for that kind of combined lasting appeal (ChiTingTing, 2012). This is a major point of the application of traditional Chinese wash painting in the modern fashion clothing design.

In many cases, on the traditional Chinese wash painting color layout, blank-leaving treatment will also be adopt deliberately, giving unlimited imagination." White rice paper has a life because of the artist's ink rendering, but because of the clever blank-leaving it becomes so vivid." For example, the famous painter Zhu Da of transitional period between Ming Dynasty and Qing Dynasty ,his ink painting, it is through blank-leaving, impressionistic and other artistic works show the transcendent, ethereal profound artistic conception. And on the clothing color, appropriate space is also very important. Many people sometimes met in the street, someone wearing a very fancy clothing just like a palette ,and may feel that dress is too dazzling .However, there are some people who also wear fancy clothes but it makes public feel comfortable and enjoyable, which is actually the learning of "blank leaving". "blank-leaving" on the garment is not equal to the white paper, but refers to a proper pure sense (Chen yao, feng weiyi, 2011). Pattern is certainly beautiful itself, but unreasonable use of it in any ways may reduce people's sense of identity for the clothing itself. Actually, "little fresh" "Bohemia", the current popular style, is exactly the best cases for this. From my perspective, this process is actually a kind of fashion art "blank-leaving", which is to allow people to hold the dress, to enhance the beauty of clothing, increases people's psychological identity of clothing. 

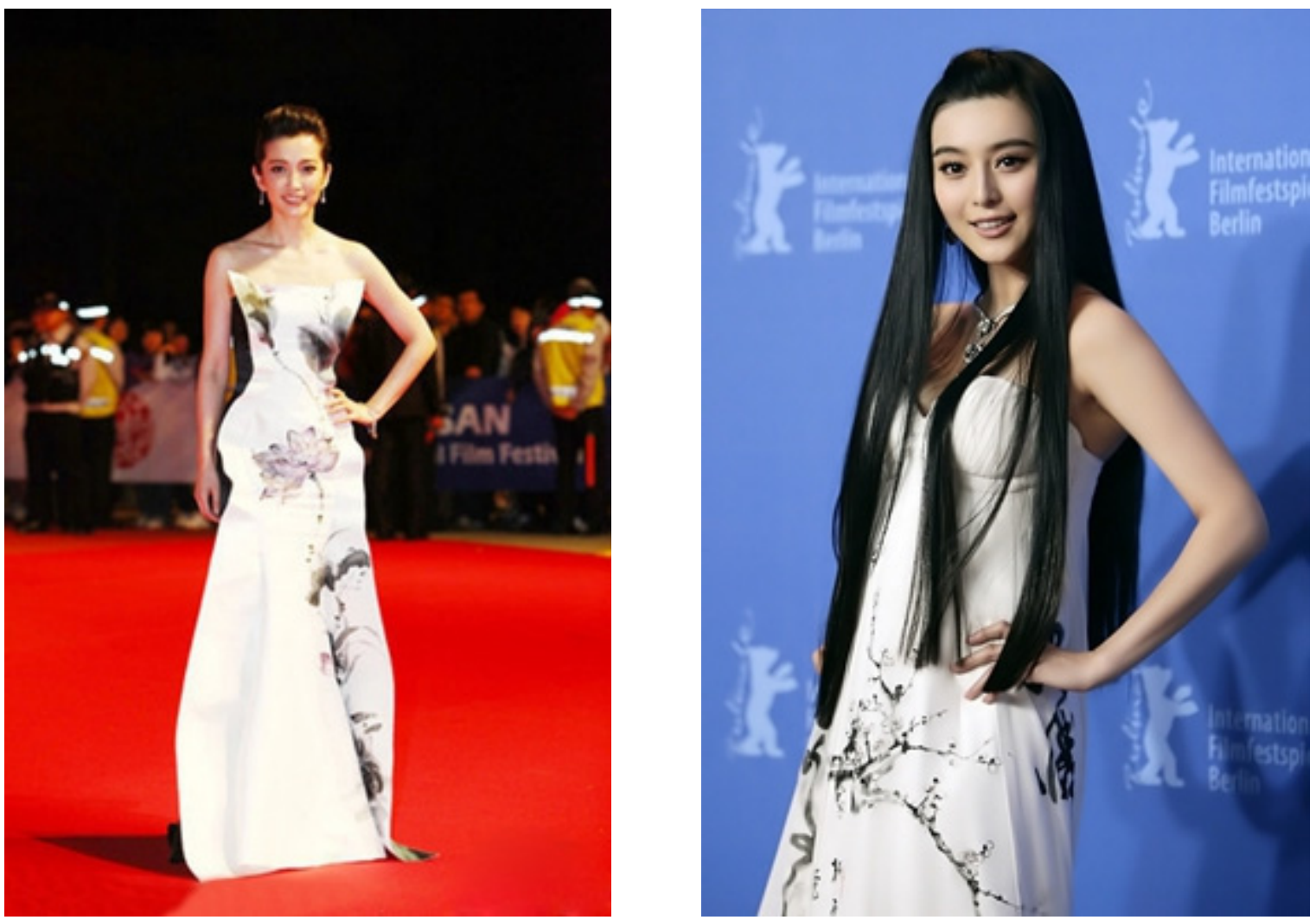

Figure 3. Ink dress by Guo Pei

Figure 4. "Go over the Snow insearch of Plums"by LawrenceXu

\section{3 the connectivity on emotion}

Due to the influence of Confucianism, Chinese traditional painting emphasizes a kind of implicit beauty. It is not like western painting putting strong emphasis on the perspective of image, but stresses subjective feeling along with the gender, free and easy. From the point of view of Operation skill related to traditional Chinese wash painting, three methods generally are applied for emotional expression, including "repeat", "changes", "leaving". (Yuan Dapeng, Liao Chenlu, 2011) "repeat", is the kind of repetition when drawing, just like the repeating notes in music which have a sense of rhythm .After the use of repetition, the changes make whole picture rich, fun and lively. "leaving" refers to the blank-leaving on color and screen. It is the mixed use of these that form a traditional Chinese wash painting with unique characteristics. In such a painting, emotion conferred of artist, just as art form, is restrained and subtle but full of flavor.

In costume design, sometimes a kind of subtle emotional expression is also attached. Western clothing system pays attention to personality and novelty creation and focus on sexy imaginative clothing styles. (Yang Yichen, 2010) Obviously, this is related to the westerners' personality, pursuing freedom and open-minded. Their clothing art is undoubtedly a good interpretation of this emotion. However, for Chinese clothing art, because of deeply influenced by Chinese Confucian philosophy, it emphasizes a subtle beauty. Traditional Chinese garments are stylized wide-body style, such as Ru skirt of song dynasty (Figure 5)and the Qing dynasty dress(Figure 6),all of these embodies the characteristics of a traditional Chinese costumes, the overall tone is subtle and natural. (Yang Yan, 2010)

Throughout Chinese traditional painting art and ancient Chinese traditional costumes, the feelings they express are so similar, it is also an emotional foundation for traditional Chinese wash painting used to modern fashion design. (Gao Chuanmin, 2013) 


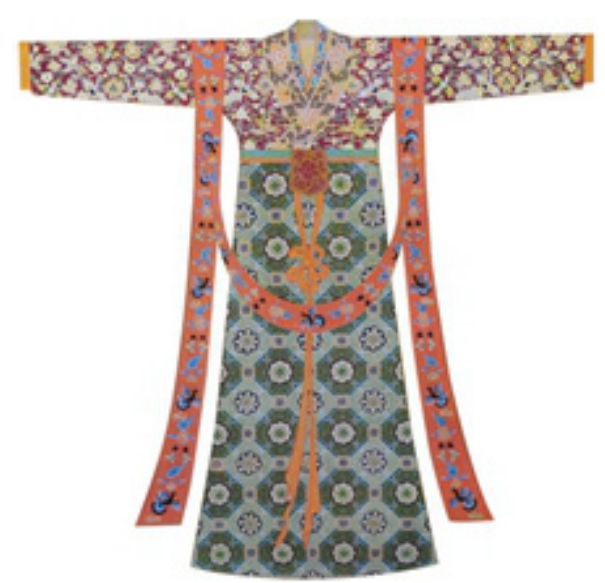

Figure 5. Ru skirt of song dynasty

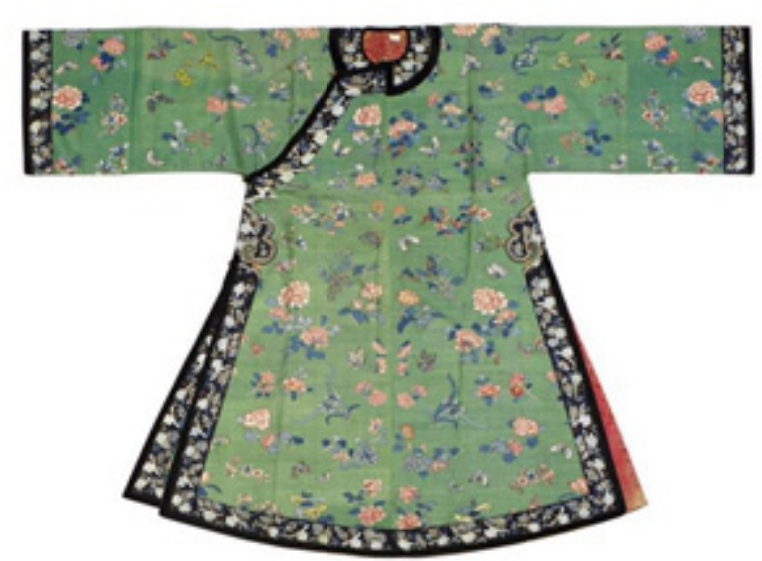

Figure 6. The Qing dynasty dress

\section{The using methods of Chinese traditional wash painting in the apparel design}

As people increasingly high demand for clothing, as one of the representative of Chinese traditional culture, Chinese traditional ink painting, the way about which applied to the fashion design shows a wide range of development, from the fabric, accessories to structure and taste.

\subsection{Printing-Scattered point}

Direct dyeing and printing wash painting on the clothing is the most directly application form, which is the most simple and intuitive way. And this can be divided into two kinds according to the layout: a large area of scattered point and small scale centralized.

The so-called scattered point is to have the more distinctive scenery (flowers, birds, still life, etc.) directly printed on the fabric through the traditional dyeing process or computer inkjet technology. The screen is large, relatively intact, with strong visual impact in this way. Ink element combined with elegant fabric will always have a special effect, or gentle, or slender, varied. The 2009 "sky" fashion show of local designers QiGang, in where the method of large area of scattered point is widely used to the clothing of ink elements so that there is a success definitely, shown in figure 7 and figure 8. 


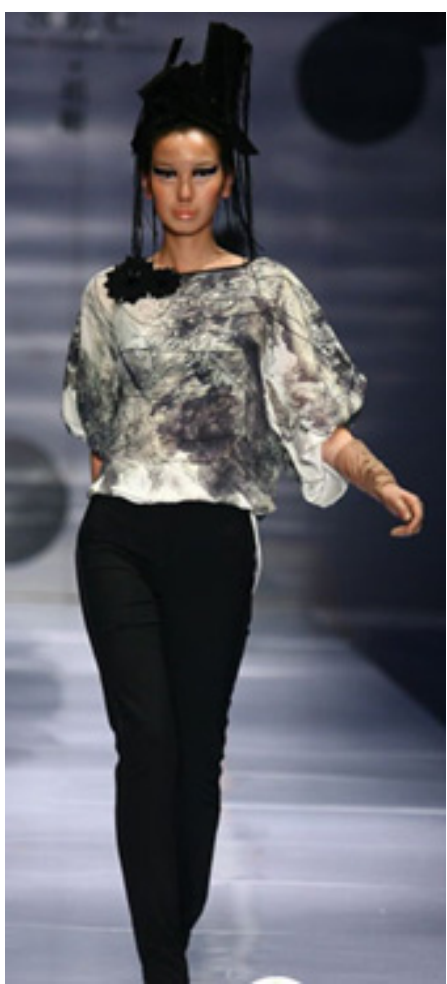

Figure 7. "Sky" by Qi Gang

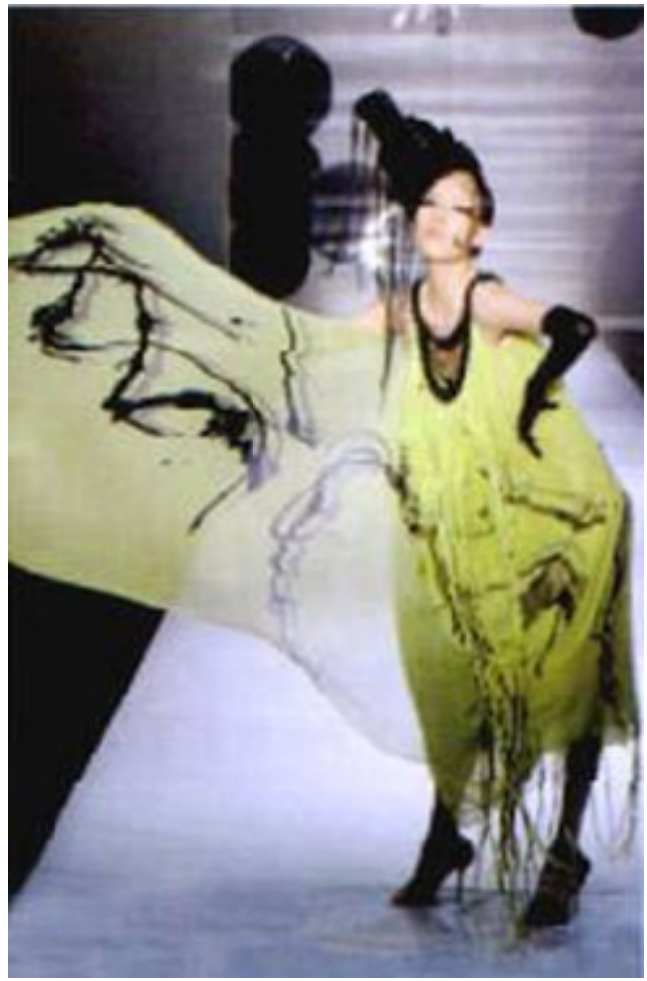

Figure 8."Sky" by Qi Gang

The application way of large area scattered point printed in the modern public fashion clothing design can also be very broad, including some popular brands which have begun to take ink art into their costume designs, such as "South commoner". There are lots of ink element and evolution element of it in its 2014 spring and summer clothing.

"South commoner", a very poetic name, as its name suggests, it praises highly the lifestyle of "natural, healthy, perfect". Natural colors, romantic style, pure fabrics, not along with the flow but always fashionable, all of these are 
its logo. We can clearly find that the clothing of this brand have a thick smell of China water town and the charm of traditional Chinese ink and the concept of this brand is so similar, so the elements of Chinese ink applied to it brand clothing is not surprising. As shown in figure 9, the pattern with characteristic of traditional Chinese ink and wash ,pine, pond, forest and other features, through a large area printing be directly printed on these three clothes. It is an example of the use of Chinese style clothing. Such a use of the method for the high-end couture perhaps somewhat simple, but for the mass clothing it is exactly proper which makes it possible that ordinary people can feel the charm of Chinese culture, meanwhile this approach is particularly suitable for mass production and process is relatively simple, reducing costs, so it is a performance of the method in line with popular fashion. As for the T-shirt, shirt design, I believe there will be more ink elements appear in our shopping mall, just like the tide brand (Mouth Monkey, Hi Panda.etc), ink element can also be a sign of branded which is a part of our Chinese people's own tide.
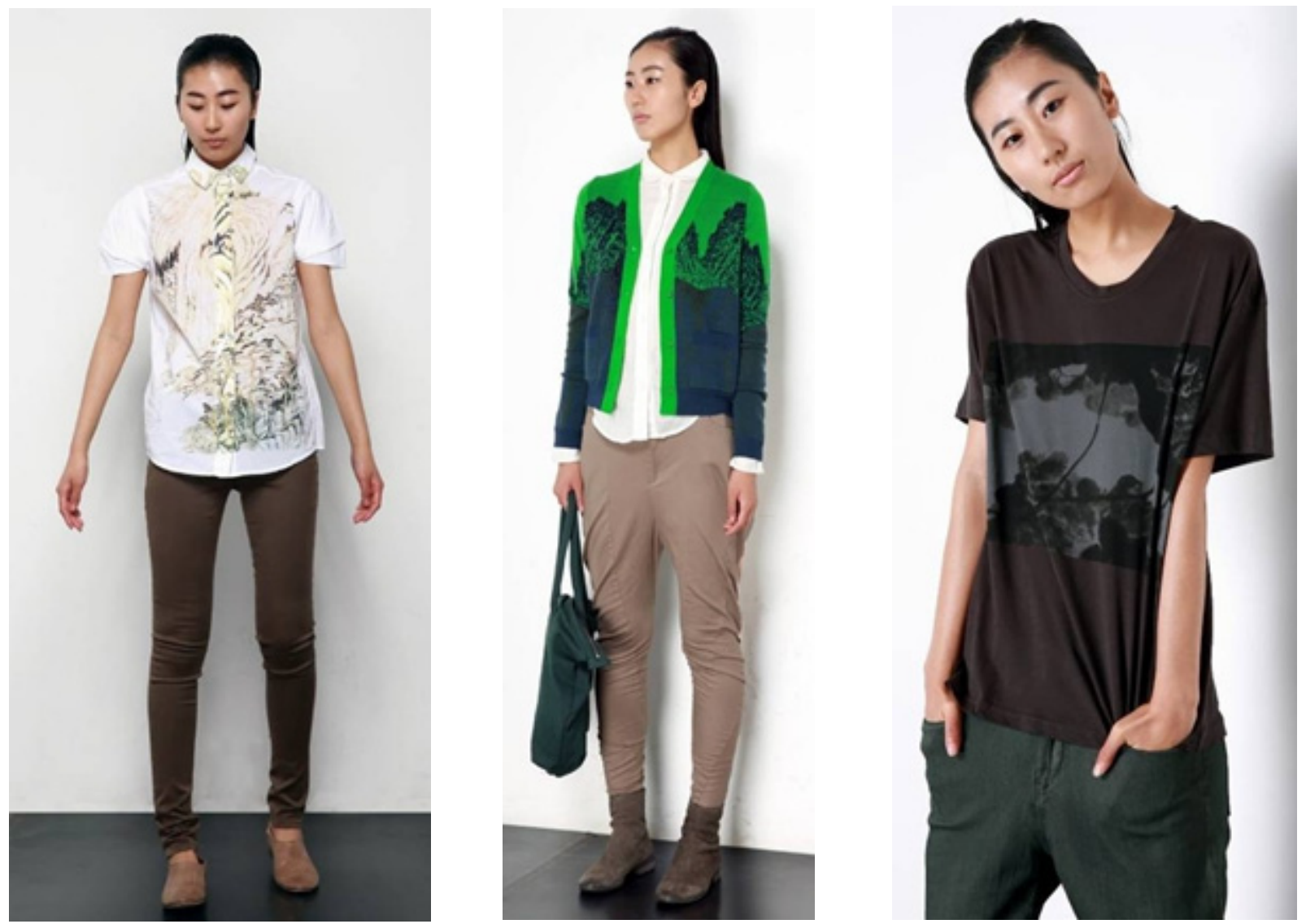

Figure 9. Ink printing clothes of "South commoner"

In fact, there is another form of expression as for the large area of scattered point of the elements of traditional Chinese ink painting in modern fashion design, it can be said to be a variant or extended use of ink art in the clothing, is an art divergence and evolution. It is not simply choose a painting or intuitive typical scene ink to be printed on clothing, but through a feeling of ink smudges, a unique ink color performance to convey a Chinese-style fashion. (Zhang Linlin, Li Chunjing, 2008) Now in fabric design, a lot of cloth of ink feeling has appeared, some like a splash of ink floating on the fabric. Color is no longer limited to black. As shown in figure 10, the first piece has ink shading effect through black and white gauze interlacing, the second is the direct use of color blending and penetration to render the ink effect, this special printing techniques are also often used in ink paintings. I have painted in the fashion course using this skill and felt the wonders of traditional Chinese art, shown in figure 11. For South commoner, this presentation form also used, a natural, comfortable brand concept is shown by splash-ink fabric. These clothes with brand characteristics are full of fashion taste and it is a good choice of clothing for the young and urban white-collar personality chasing. Through the surface, we felt a humane care, now that feels a bit like the young artists, but mature added there. 

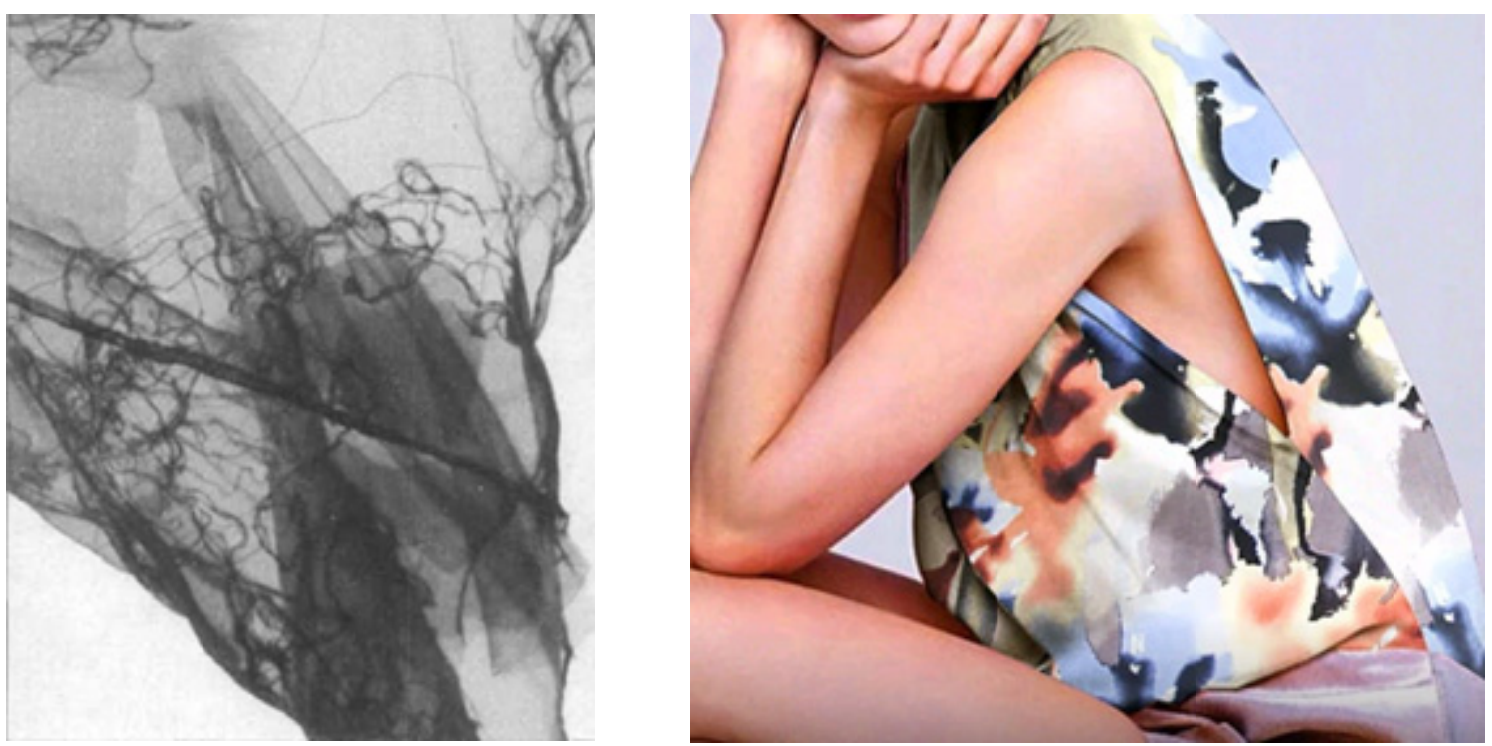

Figure 10. The disguise use of ink painting
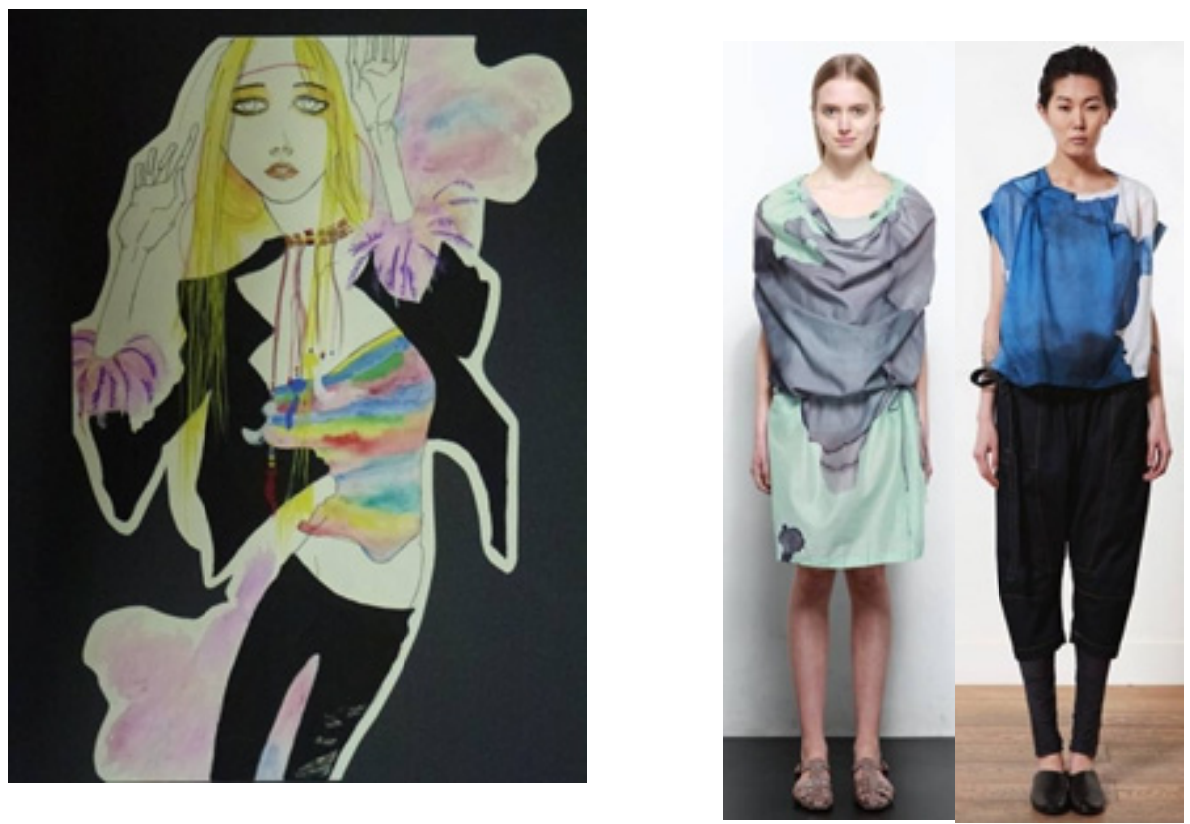

Figure 11. Fashion painting by my self

Figure 12. South commoner

\subsection{Printing—centralized}

Large area of scattered point printing way for the use of traditional Chinese wash painting in the dress is great, but such a small scale centralized way makes the ink dress with another kind of appeal, it creates a visual focus, more emphasis on the clothing of fine details.

Like the nods eyeball pen of clothing, it makes whole dress full of poetic. The use of such way generally appear in the shoulder, back, waist and sleeve, hem, such as certain parts. The basic style of pattern is given priority to with independence. (Wang Fang, 2007) There are many ink element clothing in 2012 ChuYan Spring and Summer fashion show, "listen to incense" as the theme, of which there are several pieces using a centralized printing, such as figure 13, figure 14.The piece in figure 13 inspired by the lotus leaf, by dyeing, embroidery and other traditional crafts processing, the whole garment is magnificently conceived and far-reaching conception. The dress of figure 14 is a plum in the shoulder by printing patterns, the whole garment because it's decorate instantly have a human face. (BianXiangYang, 2006) 


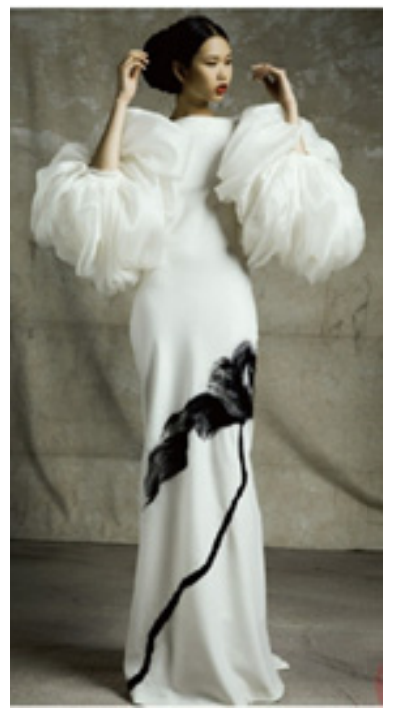

Figure 13."listen to incense"

Focus on skirt

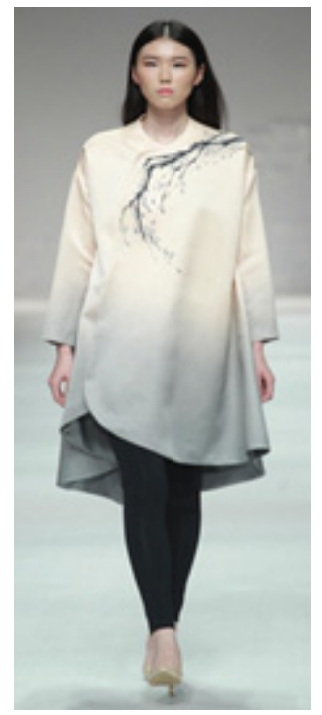

Figure 14."listen to incense"

Focus on shoulder

\section{The summary and outlook}

In the long history of China, countless cultural wealth settled down, they are inexhaustible source of inspiration for local designers. Chinese traditional wash painting, as an important part of traditional Chinese culture, with its unique beauty of ink, widely favored by domestic and foreign designers. This paper has described a few clever way for use of traditional Chinese wash painting to apparel design, but many ways for traditional Chinese wash painting applied to modern fashion remaining. Through research and analysis on this topic, the following conclusions are gotten :(1) the development prospects of Chinese traditional wash painting dress is great, now about ink clothing brand is not so much, it is as a part of Chinese traditional culture, worth designers continue to tap its unique charm applied to clothing design.(2) there are many more people are willing to accept ink chic clothing.(3)The application way of ink element on modern fashion design is still a lot, ink and fabric design elements can be cleverly combined to make "painting also clothing, clothing also painted" possible.(4) It can provide a steady stream of inspiration and material for many local designers, while to promote he Chinese traditional culture also played a significant role in this process.

\section{Acknowledgement}

This project is sponsored by Shanghai University of Engineering Science 2015-year Innovation Fund for Graduate Students.

\section{References}

BianXiangYang. (2006). Clothing Art Judgment. Shanghai: donghua university press, 2006.

Chen yao, feng weiyi. (2011). Modern Fashion Design and Chinese Traditional Painting. Grant art, 2011 (3) : 105.

ChiTingTing. (2012). Analyses the Contemporary Ink Painting in the Modern Life Language Performance. Journal of beauty with The Times, 2012 (9) : 82-83.

Elke Karoline Gaugele. (2008). Design Dictionary. Board of International Research in Design,2008.

Gao Chuanmin. (2013). Thinking about the Traditional Chinese Painting and Abstract Art. Journal of education teaching BBS, 2013 (17) : 129-130.

Gao Yuan, Zhang Yan. (2011). Ink Element - A Beautiful Scenery in the Design of Clothing. Journal of fine arts, 2011 (10) : 146.

Heinz Paetzold. (2009). The Origins of Landscape Painting: An Intercultural Perspective. Journal of Intercultural Aesthetics, 2009 (9) : 55-67.

Hu Bo, Jia jingsheng. (2010). The Rhyme of Ink Painting and Clothing Beauty of Fusion Innovation. Journal of beauty with The Times, 2010 (3) : 64-67. 
Jinxiang Ma, Xuguang Yang, \& Mingyu Gao. (2012). Interactive Research of Traditional Aesthetics and Teaching of Art and Design. Knowledge Discovery and Data Mining, 2012 (135): 511-515. http://dx.doi.org/10.1007/978-3-642-27708-5_70

Kou Yuanxun. (2006). Chinese Ink Painting Origin, Aesthetic, Performance. Yunnan university press, 2006.

Song Ningning. (2013). The Application of Ink Element in Modern Clothing Design. Modern decoration theory, 2013 (4) : 110-112.

Sun Yanan, Zhang Xing. (2009). The Traditional Chinese Ink and Wash and Dress Design Art Become Attached. Journal of fine arts, 2009 (11) : 224-225.

Wang Fang. (2007). Clothing Pattern Design. Shanghai: Shanghai people's fine arts publishing house, 2007:109.

Wang Feifei. (2002). The Beauty of the Black and White of the Ink Painting. Art and Design, 2002 (2): 64-66.

Wu Shanming. (2010). (Ed.). Ink Painting Association, A Collection of Chinese Contemporary Ink Painting Masters. Beijing: China academy of fine arts publishing house, 2010.

Xue Shuqin. (2006). The Adornment of Traditional Ink Painting Spirit. 2006 (5) : 30 and 31.

Yang Yan. (2010). Chinese Ink Painting in the Modern Clothing Packaging Design Art. Journal of taiyuan city vocational and technical college, 2010 (6) : 162-164.

Yang Yichen. (2010). Ink Painting in the Clothes Dress - Explore the Combination of Ink Painting and Clothing Art Forms. Journal of beauty with The Times, 2010 (11) : 103-106.

Yuan Dapeng, Liao Chenlu. (2011). Ink Painting and Clothing. Hundreds of art, 2011 (2) : 182-183.

Zhang Linlin, Li Chunjing. (2008). Fashion Oriental Complex. Journal of textile and apparel weekly, 2008 (7) : 42-43.

Zhou Meng. (2009). East to the West- International Fashionable Landscape of China Fashion. Journal of China textile, 2009 (7) : 96-98. 